\title{
Incorrectness of the method of calculating cargo fastening on railway platforms
}

\author{
Khabibulla Turanov ${ }^{1, *}$, Yadgor Ruzmetov ${ }^{2}$, and Jamol Shikhnazarov ${ }^{2}$ \\ ${ }^{1}$ Tashkent State Technical University named after Islam Karimov, University Str., 2, 100174, \\ Tashkent, Uzbekistan \\ ${ }^{2}$ Tashkent Railway Engineering Institute, Temirylchilar Str., 1, 100167, Tashkent, Uzbekistan
}

\begin{abstract}
Inaccuracy of the existing methodology for calculating cargo fastening. Cargo fastening by flexible and retention elements. The paper should define the "shearing" force across the car as the sum of the transverse transport inertia and wind load, taking into account the safety factor from tipping over; determine the transverse force perceived by the means of securing the load, taking into account the reaction of the retention bars of only one direction; calculate the forces in the elastic fasteners when exposed to shearing forces, taking into account the geometry of the fasteners according to existing methods. The research methods are based on the basic law of dynamics for the relative motion of a material point, where the transverse and vertical transferring inertia forces are formally assigned to external forces. The paper proves that according to the existing methodology, the force in all elastic cargo fasteners under the influence of transverse forces has the same value, regardless of the different arrangement of the geometric parameters of the fasteners in space. This is not true. The calculations of forces in the elastic fastening elements according to Appendix 8 of the existing methodology are given. Under the influence of transverse forces, the strength of the first and second pairs of elastic fasteners, both one and the other direction, are not provided by the method of Appendix 8 - the forces in the fasteners are greater than the permissible one $(24.8$ $\mathrm{kN})$. Existing calculation methods do not ensure the strength of the cargo fastening elements.
\end{abstract}

\section{Introduction}

The problems of securing cargo in rail, road and sea transport are described in [1-24]. For example, in [1], the results of both analytical and experimental studies on securing various cargoes on railway cars (see pp. 35-60, 100-128 in [1]), auto and sea transport are widely presented. In [1], there are the results of calculations of securing cargo with retention bars that are attached to the car floor with nails (see pp. 64-77 in [1]). Here, when calculating the vertical and horizontal acceleration, the value of the static coefficient of friction (i.e.

\footnotetext{
* Corresponding author: khturanov@yandex.ru
} 
friction coupling) between the wooden floor of the car and the nails is 0.3 [1, p. 75-77], which is less than the recommended value - 0.45 [16]. In addition, in [1], all analytical formulas were obtained using the d'Alembert principle, where the inertia force is fictitious $[5,15]$. The inertia force of the d'Alembert has no object of action. For this reason, in theoretical mechanics $[5,15]$, the d'Alembert inertia force is included in the condition of the balance of forces only because the acceleration of body motion is taken into account. However, for example, in [1, pp. 87], the force in the fasteners (or lashings) is considered known, and the acceleration is determined, for example, in the vertical and transverse directions. Then, the magnitude of these accelerations is compared with the recommended values of the acceleration of the car, which appear when they move along rail tracks. As an example, we show the analytical formulas presented in [1, pp. 87].

Equilibrium of forces:

$$
\begin{gathered}
\uparrow \quad R-m \mathrm{~g}-2 n F \sin \alpha=m a_{v} \quad \Rightarrow \quad R=m\left(a_{v}+\mathrm{g}\right)+2 n F \sin \alpha ; \\
\rightarrow \quad F_{f}=m a_{t} \quad \Rightarrow \quad a_{t}=\frac{F_{f}}{m},
\end{gathered}
$$

Where $R$ is the normal component of the coupling reaction $(\mathrm{N}) ; m$ - mass of cargo $(\mathrm{kg})$; $g$ - acceleration of gravity; $n$-number of lashings (PCs); $F$ - effort in lashing (determined experimentally) $(\mathrm{N}) ; \alpha$ - angle of inclination of the lashing relative to the transverse axis (degree); $a_{v}$ - acceleration in the vertical direction $\left(\mathrm{m} / \mathrm{s}^{2}\right) ; F_{f}$ - tangent component of the coupling reaction or Force of friction $(\mathrm{N}) ; a_{t}$ - acceleration in the horizontal direction $\left(\mathrm{m} / \mathrm{s}^{2}\right)$.

From this it is clear that the lashing force $F$ is a known quantity that is determined experimentally. Although, the effort in the lashing $F$ is an unknown value [15].

Force of friction:

$$
F_{f}=\mu R=\mu\left[m\left(a_{v}+\mathrm{g}\right)+2 n F \sin \alpha\right]
$$

Where instead of the coefficient of friction of coupling [15], the coefficient of friction of sliding is used $\mu=f$.

Transverse acceleration as function of the pretension in the lashing $F$ :

$$
a_{t}=\frac{F_{f}}{m}=\mu\left[\left(a_{v}+\mathrm{g}\right)+\frac{2 n F \sin \alpha}{m}\right] \text {. }
$$

With the original data: $m=30$ ton $\left(30 \cdot 10^{3} \mathrm{~kg}\right), n=2(\mathrm{PCs}), \alpha=45^{\circ}, f=0.3, a_{v}=-3 \mathrm{~m} / \mathrm{s}^{2}$, $F=4(\mathrm{kN})(4000 \mathrm{~N})$ these precautions give the following equation, $\mathrm{m} / \mathrm{s}^{2}$ :

$$
a_{t}=\mu\left[\left(a_{v}+\mathrm{g}\right)+\frac{2 n F \sin \alpha}{m}\right]=0.3 \cdot\left[(-3+9.81)+\frac{2 \cdot 2 \cdot 4000 \cdot \sin 45^{\circ}}{30000}\right]=2.2 \text {. }
$$

If the vertical acceleration is neglected, the following equation may be derived $\left(\mathrm{m} / \mathrm{s}^{2}\right)$ :

$$
a_{t}=\mu \mathrm{g}+\frac{2 n F \sin \alpha}{m}=0.3 \cdot 9.81+\frac{2 \cdot 2 \cdot 4000 \cdot \sin 45^{\circ}}{30000}=3.1
$$

It is concluded in [1, p. 88] that the max transverse acceleration that an arrangement secured by top-over lashings designed according to the UIC guidelines for a cargo weight 
of 30 ton is thus $2.2\left(\mathrm{~m} / \mathrm{s}^{2}\right)$ if the vertical acceleration is set to $-3.0\left(\mathrm{~m} / \mathrm{s}^{2}\right)$ and $3.1\left(\mathrm{~m} / \mathrm{s}^{2}\right)$ if it's set to zero.

As can be seen, a special case of securing the cargo with lashings is considered in [1, pp. 87], since only the angle of their inclination $\alpha$ relative to the transverse axis $\left(\alpha=45^{\circ}\right)$ is taken into account, i.e. lashings are located perpendicular to the longitudinal axis of the car. As can be seen, in contrast to $[5,15]$, in [1], there is no concept at all about the transferring inertia forces that are really perceived by the cargo fastening elements, about "shearing" and "retentive" forces across the car. In [9], methods of fastening cargo of various configurations (for example, wheeled and tracked vehicles) with chain fastenings, ropes (or cables), as well as retention bars to the frame of vehicles are described. In [10, pp. 25-35, 85-87 and 90-92], the developed schemes of fastening cargoes of wheeled and tracked vehicles with chain fastenings to the frame of vehicles are given. Apparently, these schemes are verified by experimental tests, since there are no calculations of cargo fastening in it. The incorrectness of the formulas of the existing methodology for calculating flexible cargo fastening elements [19] are described in [13-16].

To ensure the delivery time and safety of various kinds of goods that are transported on open rolling stock, the correctness of the available methods for calculating cargo fastening is important.

The paper considers an example of calculating the fastening of a specific cargo on a railway platform according to the existing methodology.

Object:

- determination of the "shearing" force across the car as the sum of the lateral transferring inertia forces and wind load, taking into account the safety factor from tipping over;

- calculation of the friction force when the cargo is coupled to the floor of the car, taking into account the effects of the vertical transferring inertia forces;

- finding the "shearing" force perceived by the elastic fastening elements of the cargo across the car, taking into account the friction forces of coupling and sliding;

- determination of lateral forces perceived by means of cargo fastening, taking into account the reaction of the retention bars of only one direction;

- calculation tension in the elastic fastening elements under the influence of shearing force, taking into account the geometry of the fasteners according to existing methods.

\section{Research methods}

The research methods are based on the basic law of dynamics for the relative motion of a material point $[5,15]$, where lateral and vertical transferring inertia forces are formally assigned to external forces. In contrast to [1], the concepts of "shearing" and "retentive" forces across the car were used $[5,15]$. At the same time, the determination of the cargo fastening forces was carried out using the formulas of the existing calculation methods [19].

\section{Research results}

The results of the calculations of forces in flexible elements of cargo fastening on a railway platform are presented below (see fig. 1 in [24]). 


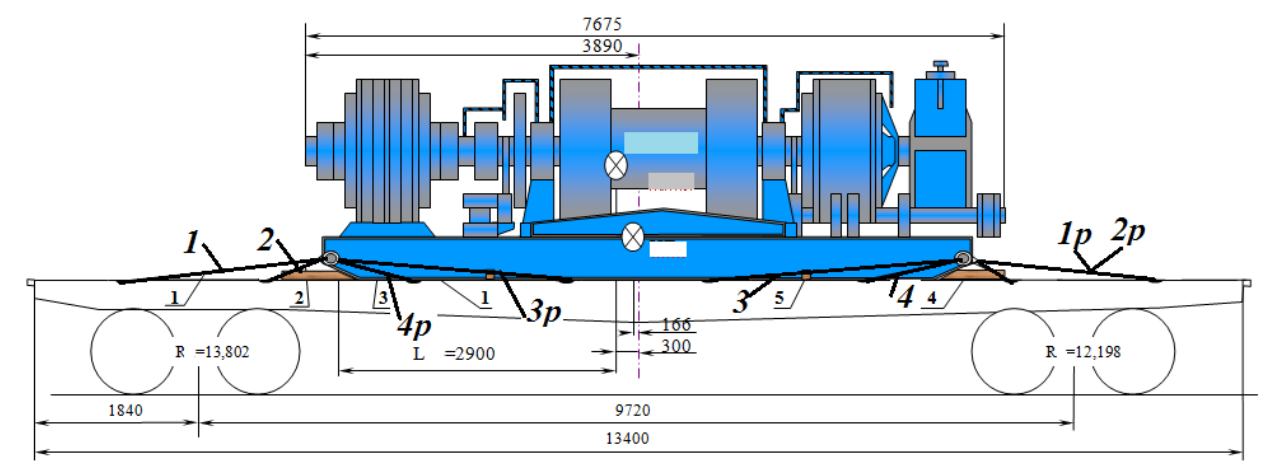

a) main view

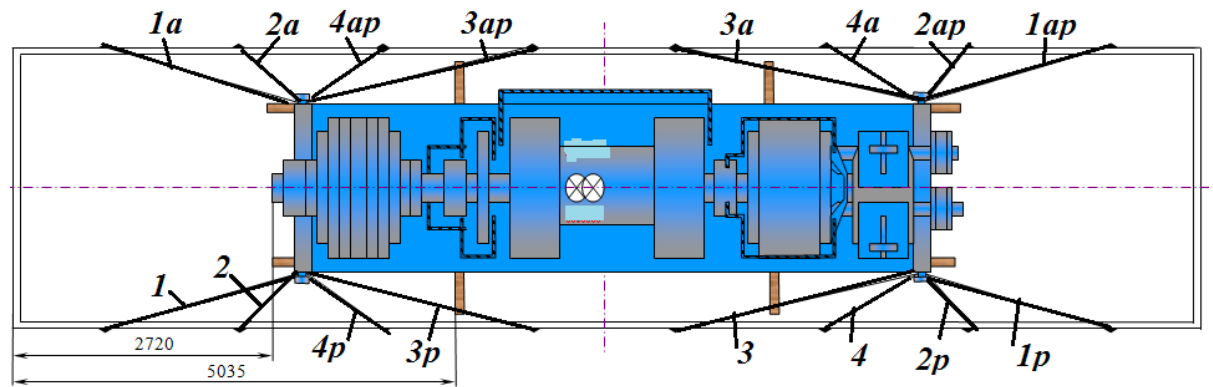

b) top view

In fig. $1,1-4,1 a-4 a ; 1 p-4 p, 1 a p-4 a p$ - numbers of elastic fasteners of one or the other direction [24].

Fig. 1. Scheme of placement and fastening of cargo on the platform: a) - main view; b) - top view.

\subsection{Mathematical description of the problem solution}

In contrast to [1, pp. 87], where all analytical formulas are obtained using the d'Alembert principle, where the inertia force is fictitious, below we will calculate the transferring inertia forces that arise when the car moves both in the transverse and in the vertical direction. As is known $[5,15]$, these forces are actually perceived by the elastic elements of cargo fastening. Also, unlike [1], we use the concepts of "shearing" and "retentive" forces across the car $[5,15]$.

The calculation of the forces perceived by elastic and retention fasteners, according to the formulas given in [15], using the Mathcad system [25], can be presented in the following sequence.

Lateral transient force of inertia $I_{e y}$ acting on the fasteners across the car (see formula (1) in [23]) $(\mathrm{kN})$ :

$$
I_{e y}=k_{\mathrm{tol} . y} G
$$

where $k_{\text {tol. } y}=a_{e y} / \mathrm{g}$ is the transverse car dynamics factor (transverse translational acceleration of a loaded car as a fraction of $\mathrm{g}$ ); $a_{e y}$ is the transverse translational acceleration of the car $(0.46 \div 0.55)\left(\mathrm{m} / \mathrm{s}^{2}\right)$, while according to [1, pp. 26-28] $0.5 \pm 0.3 \mathrm{~g}]\left(\mathrm{m} / \mathrm{s}^{2}\right) ; G$ is the gravitational force of the solid cargo $(\mathrm{kN})$. 
For the input data: $a_{e y}=0.52 \mathrm{~g}, k_{\text {tol. } y}=a_{e y} / \mathrm{g}=0.52$ and $G=260(\mathrm{kN})$ :

$$
I_{e y}=k_{\mathrm{tol} . y} G=0.52260=135.2
$$

Vertical transient force of inertia $I_{e z}$ perceived by elastic fasteners (see formula (2) in [23]) $(\mathrm{kN})$ :

$$
I_{e z}=k_{\text {tol.z }} G
$$

where $k_{\text {tol } z}=a_{e z} / \mathrm{g}$ is the vertical car dynamics factor (vertical translational acceleration of a loaded car as a fraction of $\mathrm{g}$ ); $a_{e z}=0.62 \mathrm{~g}$ is the vertical translational acceleration of the car $(0.46 \div 0.66)\left(\mathrm{m} / \mathrm{s}^{2}\right)$, while according to [1, pp. $\left.26-28\right]-1.0 \pm 0.3 \mathrm{~g}$ $\left(\mathrm{m} / \mathrm{s}^{2}\right)$.

For the input data: $a_{e z}=0.62 \mathrm{~g}, k_{\mathrm{tol} z}=a_{e z} / \mathrm{g}=0.62$ and $G=260(\mathrm{kN})$ :

$$
I_{e z}=k_{\mathrm{tol} . \mathrm{z}} G=0.62260=161.2
$$

Calculating the aerodynamic drag (wind load) affecting the windward surface area of the solid cargo (see formula (3) in [23]):

$$
F_{\mathrm{w}}=0.5 A_{\text {wind. }}
$$

Here, 0.5 is a factor of adjustment for the windward surface of the cargo, $\left(\mathrm{kN} / \mathrm{m}^{2}\right)$; $A_{\text {wind. }}$ is the windward surface area of the cargo $\left(\mathrm{m}^{2}\right)$ found by the formula:

$$
A_{\text {wind. }}=k_{\text {cont }} 10^{-6} \cdot 2 \cdot H \cdot 2 \cdot L \text {, }
$$

where $k_{\text {cont. }}$ is the factor of adjustment for the continuity of the windward surface area; $2 \cdot \mathrm{L}$ - the length of cargo, $\mathrm{m} ; 2 \cdot \mathrm{H}$ - the height of cargo, m; $2 \cdot \mathrm{L}$ - the length of cargo, m; $2 \cdot \mathrm{H}$ the height of cargo, m; $C$ is the factor of adjustment for the windward surface; $\rho_{w}$ is the air density $\left(\mathrm{kg} / \mathrm{m}^{3}\right) ; v_{\mathrm{w}}$ is the wind speed $(\mathrm{m} / \mathrm{s})$.

For input data $k_{\mathrm{c}}=0.75 ; 2 \cdot \mathrm{L}=7.674 \times 10^{3} ; 2 \cdot \mathrm{H}=2.42 \times 10^{3} ; c=0.96 ; \rho_{\mathrm{B}}=1.29$; $\mathcal{V}_{\mathrm{B}}=28.4$, and substituting in (3) and (4), we obtain:

$$
\begin{gathered}
A_{\text {wind. }}=k_{\text {cont. }} 10^{-6} \cdot 2 \cdot H \cdot 2 \cdot L=0.75 \cdot 10^{-6} \cdot 2.42 \times 10^{3} \cdot 7.674 \times 10^{3}=13.928\left(\mathrm{~m}^{2}\right) \\
F_{\mathrm{w}}=0.5 A_{\text {wind. }}=0.513 .928=6.964(\mathrm{kN})
\end{gathered}
$$

Finding a "shearing" force across the car (see formula (7) in [23]) $(\mathrm{kN})$ : 


$$
F_{\text {shear. } y}=F_{y}=k_{\text {saf. }}\left(I_{e y}+F_{\mathrm{w}}\right)
$$

where $k_{\text {saf. }}$ is the safety factor (or roll stability factor, usually $k_{\text {saf. }}=1.25$ [5, p. 131].

For the input data $k_{\text {saf }}=1.25, I_{e y}=135.2$ and $F_{\mathrm{w}}=6.956(\mathrm{kN})$ :

$$
F_{\text {shear. } y}=F_{y}=1.25(135.2+6.956)=177.695
$$

Friction force upon coupling of cargo to the car floor (see formula (3.10) in [15]), taking into account the effect of vertical transferring inertia forces $I_{e z}$ (see formula (2) or formula (5) in [23]) (kN):

$$
F_{\text {fr.coup. } y}=f_{\text {fr.coup. }}\left(G-I_{e z}\right)=f_{\text {fr.coup. }} G\left(1-k_{\text {tol } z}\right),
$$

where $f_{\text {fr.coup. }}$ coefficient of friction of coupling (metal on wood $f_{\text {fr.coup. }}=0.4$ ).

For the input data $k_{\mathrm{tol} z}=0.62$ and $G=260(\mathrm{kN})$ :

$$
F_{\text {fr.coup. } y}=0.4260(1-0.62)=39.52
$$

As can be seen, in contrast to [1, pp. 87], the friction force of coupling, and not slipping is considered, taking into account the coefficient of vertical dynamics of the car in fractions of $g$.

Determination of the "shearing" force perceived by the elastic elements of cargo fastening across the car, taking into account the friction force of coupling (see formula (8) in [23]) $(\mathrm{kN})$ :

$$
\Delta F_{\text {coup.y }}=F_{\text {shear.y }}-F_{\text {fr.coup. } y},
$$

Substituting the input data $F_{\text {shear. } y}=177.695, F_{\text {ff.coup. } y}=39.52$ and $F_{\text {ff. } y}=27.664$ in formula (7), we have $(\mathrm{kN})$ :

$$
\Delta F_{\text {coup.y } y}=F_{\text {shear. } y}-F_{\text {fr.coup. } y}=177.695-39.52=138.185
$$

The reactions of the retention bars can be found by the formulas (see (47) Appendix 3 [19] or formula (10) in [23])):

$$
R_{\text {bar. } y}=k_{1} n_{\text {nail.y }} n_{\text {bar. } y}\left[R_{\text {nail }}\right]
$$

where $k_{1}=0.6$ is the holding strength of retention bars adjusted for the car floor condition, pcs, usually assumed to be equal to $0.5 \div 0.8$, provided that the cargo outline effectively prevents using more nails; else, $1.5 \div 2.0 ; n_{\text {nail. } y}=5$ is the assumed required number of fasteners (nails) for each retention bar (PCs); $n_{\text {bar. } y}=2$ is the assumed number of retention bars as shown in the cargo placement and securing diagram, PCs (see fig. 1); 
$\left[R_{\text {nail }}\right]=1.08$ is the acceptable limit of force acting on a single $\varnothing 6 \mathrm{~mm}, 150$ to $200 \mathrm{~mm}$ long fastener (nails), (see table 32 Appendix 3 [19]) (kN).

Substituting the initial data in the formula (8), we obtain the reaction values of the retention bars with the accepted number of fasteners (nail) $(\mathrm{kN})$ :

$$
R_{\text {bar. } y}=k_{1} n_{\text {nail } . y} n_{\text {bar. } y}\left[R_{\text {nail }}\right]=0.6 \cdot 5 \cdot 2 \cdot 1.08=6.28 \text {. }
$$

Determination of the transverse force $\Delta \mathrm{F}_{\text {bar.coup.y }}$ perceived by means of cargo fastening without taking into account the elastic and frictional forces from the preliminary twists of the wire, but taking into account the reaction of the retention bars $R_{\text {bar.y }}$ in only one direction, according to the formula $[15,16]$ :

$$
\Delta F_{\text {bar.coup. } y}=\Delta F_{\text {coup } y}-R_{\text {bar. } y} .
$$

Substituting the initial data calculated by formulas (7) in (9), we obtain $(\mathrm{kN})$ :

$$
\Delta F_{\text {bar.coup. } y}=138.185-6.48=131.695
$$

As can be seen, there will obviously be a transverse shift of the cargo, since $\Delta F_{\text {barp.coup. } y}$ $>R_{\text {bar.y }}$, i.e. the cargo must be secured against shear. In this case, the retention bars will lose contact with the wooden floor of the car.

\subsection{Results of calculations of forces in cargo fastenings on the car using the formulas in Appendix 3 [19]}

The forces (i.e. internal forces) in the cargo fastening of both one and the other direction under the action of transverse forces are determined by the formulas (see formula (40) in [19]), which for the convenience of calculation we presented in the form:

$$
R_{k y}=\frac{\Delta F_{\text {bar.coup. } y}}{c} \quad(k=1,2 ; \quad c \in\{d 1, d 2\}),
$$

where $\Delta F_{\text {bar.coup. } y}$ - lateral force, perceived by elastic and retention fastening elements (see formula (9), where $\Delta F_{\text {bar.coup.y }}=131.695(\mathrm{kN})$ );

$d 1$ and $d 2$ - dimensionless constant numbers, which are determined through the specified values of the physico-geometric parameters of wire fasteners in the form:

$$
\begin{aligned}
& d 1=\left(f_{\text {сц }} \times \frac{h_{i}}{l_{i}}+\frac{b_{i}}{l_{i}}\right)+\left(f_{\text {сц }} \times \frac{h_{i p}}{l_{i p}}+\frac{b_{i p}}{l_{i p}}\right) ; \quad \\
& d 2=\left(f_{\text {сц }} \times \frac{h_{i a}}{l_{i a}}+\frac{b_{i a}}{l_{i a}}\right)+\left(f_{\text {сц }} \times \frac{h_{i a p}}{l_{i a p}}+\frac{b_{i a p}}{l_{i a p}}\right) .
\end{aligned}
$$

Here $h_{i}, b_{i}$ and $l_{i} ; h_{i p}, b_{i p}$ and $l_{i p} ; h_{i a}, b_{i a}$ and $l_{i a} ; h_{i a p}, b_{i a p}$ and $l_{i a p}-$ the values of the projection of the elastic fasteners of one or the other direction on the vertical and lateral axis of the car, respectively, calculated according to the drawing, and the length of these fasteners $(\mathrm{m})$.

The geometric parameters of the fasteners are summarized in table 1. 
Table 1. Geometry of the securing devices (m).

\begin{tabular}{|c|c|c|c|c|c|}
\hline $\begin{array}{l}\text { Designation of } \\
\text { the securing } \\
\text { devices }\end{array}$ & $\begin{array}{l}\text { Direction of } \\
\text { securing }\end{array}$ & \multicolumn{4}{|c|}{$\begin{array}{c}\text { The values of the projections of the securing devices and } \\
\text { their length }(\mathrm{m})\end{array}$} \\
\hline$h_{i}$ & \multirow{6}{*}{ One direction } & 0.302 & 0.302 & 0.302 & 0.302 \\
\hline$b_{i}$ & & 0.572 & 0.572 & 0.572 & 0.572 \\
\hline$l_{i}$ & & 2.059 & 0.854 & 2.143 & 1.044 \\
\hline$h_{i a}$ & & 0.302 & 0.302 & 0.302 & 0.302 \\
\hline$b_{i p}$ & & 0.572 & 0.572 & 0.572 & 0.572 \\
\hline$l_{i a}$ & & 2.059 & 0.854 & 2.143 & 1.044 \\
\hline$h_{i p}$ & \multirow{6}{*}{$\begin{array}{l}\text { The other } \\
\text { direction }\end{array}$} & 0.302 & 0.302 & 0.302 & 0.302 \\
\hline$b_{i a}$ & & 0.572 & 0.572 & 0.572 & 0.572 \\
\hline$l_{i p}$ & & 2.059 & 0.799 & 2.31 & 0.977 \\
\hline$h_{\text {iap }}$ & & 0.302 & 0.302 & 0.302 & 0.302 \\
\hline$b_{\text {iap }}$ & & 0.572 & 0.572 & 0.572 & 0.572 \\
\hline$l_{\text {iap }}$ & & 1.977 & 0.799 & 2.31 & 0.977 \\
\hline
\end{tabular}

Also note that here the diameter of the fastener wire and the number of threads in the fasteners are taken equal to $\varnothing=6(\mathrm{~mm})$ and $\mathrm{n}=8(\mathrm{PCs})$, respectively.

Substituting data of Table 1 in formulas (11) and (12), taking into account the fact that the coefficient of friction of coupling $f_{\text {fr.coup. }}=0.4$, we will have:

$$
\begin{aligned}
& d 1=\left(\begin{array}{l}
\left(0.4 \times \frac{0.302}{2.059}+\frac{0.572}{2.059}\right)+\left(0.4 \times \frac{0.302}{0.854}+\frac{0.572}{0.854}\right)+\left(0.4 \times \frac{0.302}{2.143}+\frac{0.572}{2.143}\right)+ \\
+\left(0.4 \cdot \frac{0.302}{1.044}+\frac{0.572}{1.044}\right)+\left(0.4 \times \frac{0.302}{2.059}+\frac{0.572}{2.059}\right)+\left(0.4 \times \frac{0.302}{0.799}+\frac{0.572}{0.799}\right)+ \\
+\left(0.4 \times \frac{0.302}{2.31}+\frac{0.572}{2.31}\right)+\left(0.4 \times \frac{0.302}{0.977}+\frac{0.572}{0.977}\right)
\end{array}\right)=4.348 \\
& d 2=\left(\begin{array}{l}
\left(0.4 \times \frac{0.302}{2.059}+\frac{0.572}{2.059}\right)+\left(0.4 \times \frac{0.302}{0.854}+\frac{0.572}{0.854}\right)+\left(0.4 \times \frac{0.302}{2.143}+\frac{0.572}{2.143}\right)+ \\
+\left(0.4 \cdot \frac{0.302}{1.044}+\frac{0.572}{1.044}\right)+\left(0.4 \times \frac{0.302}{1.977}+\frac{0.572}{1.977}\right)+\left(0.4 \times \frac{0.302}{0.799}+\frac{0.572}{0.799}\right)+ \\
+\left(0.4 \times \frac{0.302}{2.31}+\frac{0.572}{2.31}\right)+\left(0.4 \times \frac{0.302}{0.977}+\frac{0.572}{0.977}\right)
\end{array}\right)=4.362
\end{aligned}
$$

Substituting the obtained values of dimensionless constant numbers $d 1$ and $d 2$ into formula (10), and taking into account the asymmetry of the location of the fastening elements relative to the lateral axis of both one and the other direction, we obtain $(\mathrm{kN})$ :

$$
\begin{gathered}
R_{1 y}=\frac{\Delta F_{\text {bar.coup } . y}}{d 1}=\frac{131.695}{4.348}=30.288 \\
R_{2 y}=\frac{\Delta F_{\text {bar.coup } y}}{d 2}=\frac{131.695}{4.362}=30.19
\end{gathered}
$$

As can be seen, the forces in all flexible elastic cargo securing elements of one or the 
other direction under the action of lateral forces, regardless of different values of the geometrical fastening parameters (see table 1), have the same value, which does not correspond to reality. This confirms the senselessness of the method of calculating cargo fastening according to the formulas in Appendix 3 in [19] to the assessment of the safety of the transportation process, since the calculations are carried out without taking into account the forces of preliminary twisting of wire fasteners (for example, $(\mathrm{R} 0=20(\mathrm{kN}))$ to which these fasteners are subjected. In addition, according to the existing calculation method, the strength of elastic fasteners with a diameter of $\varnothing=6(\mathrm{~mm})$ and the number of threads $\mathrm{n}=8$ (PCs.) is not provided, since the forces in the fasteners are greater than the permissible value $($ Rtol. $8=24.8(\mathrm{kN}))$.

\subsection{Results of calculations of forces in cargo fastenings on the car using the formulas in Appendix 8 [19]}

In this case, we take into account that the friction coefficient of coupling $f_{\text {fr.coup. }}=0.4$, $\Delta F_{\text {bar.coup. } y}=131.695(\mathrm{kN})$ (see formula (9)). Here we emphasize that the remarks on the derivation of the formula in Appendix 8 in [19] are also well known [15]. In addition, the formulas in Appendix 8 in [19] are a special case of formulas for calculating the forces in the cargo fastening under the influence of lateral forces derived in [15, pp. 204-215].

The forces in the wire fasteners under the influence of lateral forces of both one and the other direction will be performed according to the formula (3) in Appendix 8 in [19]:

$$
\begin{gathered}
R_{i y}=Z_{k y} \times \frac{n_{i}}{l_{i}} \times \frac{b_{i}}{l_{i}} ; \quad R_{i p y}=Z_{k y} \times \frac{n_{i p}}{l_{i p}} \times \frac{b_{i p}}{l_{i p}}, \\
R_{i a y}=Z_{k y} \times \frac{n_{i a}}{l_{i a}} \times \frac{b_{i a}}{l_{i a}} ; \quad R_{\text {iapy }}=Z_{k y} \times \frac{n_{i a p}}{l_{i a p}} \times \frac{b_{i a p}}{l_{i a p}} \quad(\mathrm{k}=1,2 ; \mathrm{i}=1,4),
\end{gathered}
$$

where $Z_{k y}$ are determined by the formula (4) in Appendix 3 in [19]:

$$
Z_{k y}=\frac{\Delta F_{\text {bar.coup. } y}}{C 0_{k y}} \quad\left(k=1,2 ; \quad C 0_{k y} \in\left\{C 0_{\text {coup. } 1 \mathrm{y}}, C 0_{\text {coup. } 2 \mathrm{y}}\right\}\right) .
$$

Here $\Delta F_{\text {bar.coup. } y}$ - lateral force acting on elastic and retention fastening elements (see formula (9)) $(\mathrm{kN}) ; f_{\text {fr.coup. }}$-friction coefficient of coupling (usually 0.45$) ; c 0_{\text {coup.1y }}$ and $c 0_{\text {coup. } 2 y}$ additional parameters of elastic fasteners having a dimension $(1 / \mathrm{m})$.

Determination of additional parameters of the elastic fastening elements across the car with the friction coefficient of coupling according to the formulas obtained by the authors of the paper from (4) in Appendix 3 in [19]:

$$
c 0_{\text {coup. } 1 y}=\sum_{i=1}^{n_{\mathrm{p}}} \frac{n_{i}}{l_{i}} \times\left(f_{\text {fr.coup. }} \times \frac{h_{i}}{l_{i}}+\frac{b_{i}}{l_{i}}\right) \times \frac{b_{i}}{l_{i}}+\sum_{i=1}^{n_{\mathrm{p}}} \frac{n_{i a}}{l_{i a}} \times\left(f_{\text {fr.coup. }} \times \frac{h_{i a}}{l_{i a}}+\frac{b_{i a}}{l_{i a}}\right) \times \frac{b_{i a}}{l_{i a}}
$$




$$
c 0_{\text {coup. } 2 y}=\sum_{i=1}^{n_{\mathrm{p}}} \frac{n_{i}}{l_{i}} \times\left(f_{\text {fr.coup. }} \times \frac{h_{i p}}{l_{i p}}+\frac{b_{i p}}{l_{i p}}\right) \times \frac{b_{i p}}{l_{i p}}+\sum_{i=1}^{n_{\mathrm{p}}} \frac{n_{i p}}{l_{i p}} \times\left(f_{\text {fr.coup. }} \times \frac{h_{\text {iap }}}{l_{\text {iap }}}+\frac{b_{\text {iap }}}{l_{\text {iap }}}\right) \times \frac{b_{\text {iap }}}{l_{\text {iap }}} .
$$

Note that the geometrical parameters of the fasteners have the same values that are given in table 1 .

Substituting the initial data from Table 1 in the last formulas for $f_{\text {fr.coup. }}=0.4, \varnothing \mathrm{i}=6$ $(\mathrm{mm}), n_{i}=8$ (PCs.), we will have $(1 / \mathrm{m})$ :

$$
\begin{gathered}
c 0_{\text {coup. } .1 y}=\left[\begin{array}{l}
\frac{8}{2.059}\left(0.4 \times \frac{0.302}{2.059}+\frac{0.572}{2.059}\right) \frac{0.572}{2.059}+\frac{8}{0.854}\left(0.4 \times \frac{0.302}{0.854}+\frac{0.572}{0.854}\right) \frac{0.572}{0.854}+ \\
+\frac{8}{2.143}\left(0.4 \times \frac{0.302}{2.143}+\frac{0.572}{2.143}\right) \frac{0.572}{2.143}+\frac{8}{1.044}\left(0.4 \cdot \frac{0.302}{1.044}+\frac{0.572}{1.044}\right) \frac{0.572}{1.044}+ \\
+\frac{8}{2.059}\left(0.4 \times \frac{0.302}{2.059}+\frac{0.572}{2.059}\right) \frac{0.572}{2.059}+\frac{8}{0.799}\left(0.4 \times \frac{0.302}{0.799}+\frac{0.572}{0.799}\right) \frac{0.572}{0.799}+ \\
+\frac{8}{2.31}\left(0.4 \times \frac{0.302}{2.31}+\frac{0.572}{2.31}\right) \frac{0.572}{2.31}+\frac{8}{0.977}\left(0.4 \times \frac{0.302}{0.977}+\frac{0.572}{0.977}\right) \frac{0.572}{0.977}
\end{array}\right)=18.803 ; \\
c 0_{\text {coup. } .2 y}=\left[\begin{array}{l}
\frac{8}{2.143}\left(0.4 \times \frac{0.302}{2.143}+\frac{0.572}{2.143}\right) \frac{0.572}{2.143}+\frac{8}{1.044}\left(0.4 \cdot \frac{0.302}{1.044}+\frac{0.572}{1.044}\right) \frac{0.572}{1.044}+ \\
+\frac{8}{1.977}\left(0.4 \times \frac{0.302}{1.977}+\frac{0.572}{1.977}\right) \frac{0.572}{1.977}+\frac{8}{0.799}\left(0.4 \times \frac{0.302}{0.799}+\frac{0.572}{0.799}\right) \frac{0.572}{0.799}+ \\
+\frac{8}{2.31}\left(0.4 \times \frac{0.302}{2.31}+\frac{0.572}{2.31}\right) \frac{0.572}{2.31}+\frac{8}{0.977}\left(0.4 \times \frac{0.302}{0.977}+\frac{0.572}{0.977}\right) \frac{0.572}{0.977}
\end{array}\right]=18.85 .
\end{gathered}
$$

Finally, we obtain: $c 0_{\text {coup. } 1 y}=18.803$ and $c 0_{\text {coup. } 2 y}=18.85(1 / \mathrm{m})$.

Substituting the obtained values in the formula $(15)$, we obtain $(\mathrm{kN} \cdot \mathrm{m})$ :

$$
\begin{gathered}
Z_{y 1}=\frac{\Delta F_{\text {bar.coup } . y}}{C 0_{\text {coup. } y 1}}=\frac{131.695}{18.803}=7.004 \\
Z_{y 2}=\frac{\Delta F_{\text {bar.coup } y}}{C 0_{\text {coup } y 2}}=\frac{131.695}{18.85}=6.986
\end{gathered}
$$

The results of calculating the forces in the cargo fastening elements according to formulas (13) and (14), taking into account the calculated data obtained by formulas (9), (15) - (17), are summarized in table $2(\mathrm{kN})$. 
Table 2. Calculated forces of the securing elements in either direction $(\mathrm{kN})$.

\begin{tabular}{|c|c|c|c|c|c|}
\hline $\begin{array}{l}\text { Designations } \\
\text { of forces in } \\
\text { the securing }\end{array}$ & $\begin{array}{l}\text { Direction of } \\
\text { securing }\end{array}$ & \multicolumn{4}{|c|}{ Forces in the securing elements $(\mathrm{kN})$} \\
\hline \multirow{2}{*}{$\frac{R_{i y}}{R_{i y p}}$} & \multirow[t]{2}{*}{ One direction } & $\frac{R_{1 y}}{R_{1 y p}}$ & $\frac{R_{2 y}}{R_{2 y p}}$ & $\frac{R_{3 y}}{R_{3 y p}}$ & $\frac{R_{4 y}}{R_{4 y p}}$ \\
\hline & & $\frac{7.55}{7.55}$ & $\frac{43.985}{50.16}$ & $\frac{6.98}{6.006}$ & $\frac{29.418}{33.599}$ \\
\hline \multirow{2}{*}{$\frac{R_{\text {iay }}}{R_{\text {iapy }}}$} & \multirow{2}{*}{$\begin{array}{l}\text { The other } \\
\text { direction }\end{array}$} & $\frac{R_{1 a y}}{R_{1 \text { lapy }}}$ & $\frac{R_{2 a y}}{R_{2 a p y}}$ & $\frac{R_{3 a y}}{R_{3 a p y}}$ & $\frac{R_{4 a y}}{R_{4 a p y}}$ \\
\hline & & $\frac{7.536}{8.181}$ & $\frac{43.874}{50.034}$ & $\frac{6.963}{5.991}$ & $\frac{29.344}{33.514}$ \\
\hline
\end{tabular}

It is clear that under the influence of lateral forces, the strength of the first and second pairs of elastic fasteners of both one and the other direction is not provided by the method of Appendix 8 in [19] - the forces in the fasteners are greater than the permissible value $(24.8(\mathrm{kN}))$. Especially in the second pair of fastenings of one direction, the force exceeds the permissible one by 1.77 times $(44 / 24.8 \approx 1.7)$, and in the other direction - by 2 times $(50 / 24.8 \approx 2.0)$. As a result of this, they can be expected to be destroyed during the transportation of cargo. In other wire fasteners, the forces were less than the permissible value $(24.8(\mathrm{kN}))$. The strength of such fasteners is provided.

\section{Discussion}

The sequence of calculation of the lateral forces perceived by the wire cargo fasteners, which made it possible to find the forces in the cargo wire fasteners according to the existing method for calculating the cargo fastening according to Appendices 3 and 8 [19], is given.

The results of calculations of forces in wire fasteners according to the calculation method according to Appendix 3 in [19] showed that the strength of some fasteners with a diameter of $\varnothing=6(\mathrm{~mm})$ and the number of threads $n=8$ (PCs.) is not more than 2 times $(50 / 24.8 \approx 2.0)$. This is explained by the fact that the existing method of calculating cargo fastenings according to Appendix 3 in [19], firstly, does not take into account the force of preliminary twists of the fastening wire $R 0$, which increase the coupling force of the cargo to the car floor (estimated by the friction coefficient of coupling), and secondly, takes into account the fact that during the transportation process, cargo shifts (estimated by the friction coefficient of sliding). As you can see, the force in all wire fasteners under the influence of lateral forces, regardless of the geometry of the fasteners, have the same value (see the results of calculating the forces by formula (11)), which is not true and is one of the main disadvantages of the existing method of calculating cargo fasteners according to Appendix 3 in [19].

The results of calculations of the forces in all wire fasteners under the influence of lateral forces, depending on the fastening geometry, performed according to the formulas of Appendix 8 [19] (see table 2), have different values, which corresponds to reality and is one of the main advantages of this method. However, this method of calculating the elastic fasteners does not take into account the force of the preliminary twists of the fastening wire. According to this method, it is also not possible to predict the shift of the cargo across the 
car, and it is impossible to predict the elongation of each elastic fastener in accordance with their geometry.

In the future, in order to calculate cargo fastening, a new calculation method for the placement and fastening of cargo on a car should be applied $[15,16]$.

\section{References}

1. N. Anderson, P. Anderson, R. Bylander, S. Sokjer, B. Zether, Equipment for Rational Securing of Cargo on railway Wagons / VINNOVA Report/Rapport VR, (2004) // http://www.vinnova.se/upload / EPiStorePDF /vr-04-05.pdf.

2. M. Johanson, P. Andersson, Equipment for Efficient Cargo Securing and Ferry Fastening of Vehicles / NVF-rapporter / Va gverket, (2004). http://www.nvfnorden.org/lisalib/getfile.aspx?itemid=1593

3. Driver's Handbook Cargo Securement. A Cuide to the North American Cargo Securement Standard http://www.highwaystarmagazine.com/images /Driver_Handbook.pdf

4. European Best Practice Guidelines on Cargo Securing for Road Transport, 208. http://ec.europa.eu/transport/roadsafety/vehicles/best_practice_guidelines_en.htm

5. K.L. Komarov, A.F. Yashin, Teoreticheskaia mekhanika v zadachakh gruzovykh perevozok (Nauka, Novosibirsk, 2004)

6. J.D. Priddy, R.A. Jones, SAE Technical 1(3516), (2005)

7. J.R. Billing, Industry Practices for Loading and Securing Cargo in Vans and other Closed Trucks, Ontario Trucking Association (2006).

8. E. Hildebrand, M. Balsom, F.R. Wilson, Transportation Research Board Annual Meeting 06(1232), (2006).

9. CODE OF PRACTICE Safety of Loads on Vehicles, (2002). www.dft.gov.uk

10. TEA PAM, Tiedown Handbook for Truck Movements 55(20), 1-124 (2008)

11. Load Securement for Palletized Freight in Closed Trucks - From an Enforcement Perspective. dPE, Inc. The Science of Preventing Freight Damage, (2007).

12. Vertical cylinder handling and transportation AIGA 038/06. http://www.asiaiga.org.

13. E.N. Timukhina, Transport Problems 3(3), 65-68 (2008)

14. A. Manakov, A. Abramov, A. Ilinykh, V. Aksenov, MATEC Web of Conferences 239, 04001 (2018). DOI: 10.1051/matecconf/201823904001

15. Kh.T. Turanov, Teoreticheskaia makhanika v zadachakh gruzovykh perevozok (Nauka, Novosibirsk, 2009)

16. K. Turanov, Science and Technology 5(1), 5-14 (2015). DOI: 10.5923/j.scit.2015 0501.02).

17. V. Vorobyov, A. Manakov, I. Repina, MATEC Web of Conferences 239, 08011 (2018). DOI: 10.1051/matecconf $/ 201823908011$

18. E.N. Timukhina, A.A. Gordiienko, Transport of the Urals, 2(45), 33-37 (2015). DOI: 10.20291/1815-9400-2015-2-32-37

19. Agreement on International Goods Transport by rail "Technical conditions for allocation and fastening”. Appendix 3. Retrieved February 5, 2020. http://osjd.org/doco/public/ru

20. Kh. Turanov, Y. Ruzmetov, N. Vlasova, E3S Web of Conferences 135, 02006 (2019). https://doi.org/10.1051/e3sconf/201913502006 
21. A. Ilinykh, A. Manakov, A. Abramov, S. Kolarzh, MATEC Web of Conferences 216, 03004 (2018). DOI: 10.1051/matecconf/201821603004

22. Kh. Turanov, Y. Ruzmetov, E3S Web of Conferences 157, 01008 (2020). https://doi.org/10.1051/e3sconf/202015701008

23. Kh. Turanov, Y. Ruzmetov, E3S Web of Conferences 157, 01012 (2020). https://doi.org/10.1051/e3sconf/202015701012

24. Y. Ruzmetov, O. Molchanova, J. Shihnazarov, E3S Web of Conferences 157, 01016 (2020). https://doi.org/10.1051/e3sconf/202015701016

25. D. Kiryanov, Self-instruction Mathcad 13 (BKhV-Petersburg, SPb, 2006) 